\title{
USE OF MICRO X-RAY ABSORPTION SPECTROSCOPY AND DIFFRACTION TO DELINEATE Cr(VI) SPECIATION IN COPR
}

\author{
M. CHRYSOCHOOU ${ }^{1, *}$ \\ D.H. MOON ${ }^{2}$ \\ S. FAKRA ${ }^{3}$ \\ M. MARCUS ${ }^{3}$ \\ D. DERMATAS ${ }^{2}$ \\ C. CHRISTODOULATOS ${ }^{2}$
}

Received: $15 / 10 / 08$

Accepted: 18/12/09

\author{
${ }^{1}$ Department of Civil and Environmental Engineering \\ University of Connecticut Storrs CT 06269, U.S.A. \\ ${ }^{2}$ Stevens Institute of Technology \\ Castle poiny on Hudson, Hoboken, 07030. NJ, USA \\ ${ }^{3}$ Advanced Light Source, Lawrence Berkeley National Lab, \\ 1 Cyclotron Rd., Berkeley, 94720, CA, U.S.A
}

*to whom all correspondence should be addressed: e-mail: mchrysoc@engr.uconn.edu

\begin{abstract}
The speciation of $\mathrm{Cr}(\mathrm{VI})$ in Cromite Ore Processing Residue was investigated by means of bulk XRD, and a combination of micro-XRF, - XAS and -XRD at the Advanced Light Source (ALS), Berkeley, CA, U.S.A.. Bulk XRD yielded one group of phases that contained explicitly $\mathrm{Cr}(\mathrm{VI})$ in their structure, Calcium Aluminum Chromium Oxide Hydrates, accounting for $60 \%$ of the total $\mathrm{Cr}(\mathrm{VI})$. Micro-analyses at ALS yielded complimentary information, confirming that hydrogarnets and hydrotalcites, two mineral groups that can host $\mathrm{Cr}(\mathrm{VI})$ in their structure by substitution, were indeed $\mathrm{Cr}(\mathrm{VI})$ sinks. Chromatite $\left(\mathrm{CaCrO}_{4}\right)$ was also identified by micro$\mathrm{XRD}$, which was not possible with bulk methods due to its low content. The acquisition of micro-XRF elemental maps enabled not only the identification of $\mathrm{Cr}(\mathrm{VI})$-binding phases, but also the understanding of their location within the matrix. This information is invaluable when designing $\mathrm{Cr}(\mathrm{VI})$ treatment, to optimize release and availability for reduction.
\end{abstract}

KEYWORDS: chromium, chromite ore processing residue, X-ray Absorption spectroscopy, speciation.

\section{INTRODUCTION}

Chromite Ore Processing Residue (COPR) is generated as a by-product of the chromite ore processing to isolate and extract chromium. Chromite ore, which may be expressed by the chemical formula $(\mathrm{Mg}, \mathrm{Fe})(\mathrm{Cr}, \mathrm{Al}, \mathrm{Fe})_{2} \mathrm{O}_{4}$, is formed by means of a high-temperature (ca. 1200 ${ }^{\circ} \mathrm{C}$ ) roasting process. Addition of lime during the roasting process leads to the formation of insoluble phases that are removed as solid waste, while $\mathrm{Cr}$ is recovered in the form of soluble chromate $\left(\mathrm{CrO}_{4}{ }^{2-}\right)$ (Allied Signal, 1982). COPR has a residual chromium content, which may be up to $50,000 \mathrm{mg} \mathrm{kg}^{-1}$ total chromium, up to $50 \%$ of which may occur as $\mathrm{Cr}(\mathrm{VI})$. Hexavalent chromium is a known human carcinogen, rendering COPR a hazardous waste. To provide a basis for comparison, the $\mathrm{Cr}(\mathrm{VI})$ clean-up standard for residential use contaminated soil set by the New Jersey Department of Environmental Protection (NJDEP) is $20 \mathrm{mg} \mathrm{kg}^{-1}$, which is by two orders of magnitude less than the COPR $\mathrm{Cr}(\mathrm{VI})$ content.

There are numerous chromite ore processing plants throughout the world. Three plants were located in Hudson County, New Jersey and deposited 2.75 million tons of COPR in the period 1905-1976. Investigations at 150 residential and commercial sites led to their characterization as hazardous and studies conducted by NJDEP showed that hexavalent chromium posed a viable threat to human health in N.J. (Lioy et al., 1992). A lawsuit was enacted against the owner of a 34-acre site (denoted as SA7) on the Hackensack river in Jersey City, NJ, leading to the digging and hauling of 1.5 million tons of COPR. The site owner sought an alternative solution and initiated an extensive remedial investigation (Dermatas et al., 2006a and 2006b). 
$\mathrm{Cr}(\mathrm{VI})$ remediation is performed by reducing it to non-toxic trivalent chromium by means of chemical reductants, such as ferrous sulfate $\left(\mathrm{FeSO}_{4}\right)$ and calcium polysulfide $\left(\mathrm{CaS}_{5}\right)$. An essential prerequisite to successful treatment is the release of $\mathrm{Cr}(\mathrm{VI})$ from the solid matrix into solution, where it reacts with the added ions (ferrous iron or sulfide ions) and is reduced to $\mathrm{Cr}(\mathrm{III})$. Thus, the speciation of $\mathrm{Cr}(\mathrm{VI})$ in the solid is of fundamental importance for treatment design. Non-destructive techniques, such as X-ray Diffraction (XRD) and Scanning Electron Microscopy coupled with Energy Dispersive X-ray (SEM/EDX) can provide insight into $\mathrm{Cr}(\mathrm{VI})$ speciation, with some limitations. Chrysochoou and Dermatas (2007) employed quantitative XRD coupled with mass balances and found that approximately $50 \%$ of $\mathrm{Cr}(\mathrm{VI})$ in COPR was bound in a group of cementitious phases called Calcium Aluminum Chromium Oxide Hydrates (CACs). SEM/EDX analyses showed that there are also other cementitious phases with mixed chemical composition that contained $\mathrm{Cr}$, however, no distinction between $\mathrm{Cr}(\mathrm{III})$ and $\mathrm{Cr}(\mathrm{VI})$ could be made (Chrysochoou 2006). Hillier et al. (2007) have reported hydrogarnet as an important sink for $\mathrm{Cr}(\mathrm{VI})$, but without specific spectroscopic data to support it.

This study presents the results of speciation analyses performed on COPR coupling XRD, SEM and micro-XAS analyses.

\section{MATERIALS AND METHODS}

A representative COPR sample obtained from SA7 was used for the analyses. The sample was a grey-black granular material. A standard thin section ( $30 \mu \mathrm{m}$ thickness) of this sample was prepared using a diamond polish for microscopy and micro-XAS analyses.

The total $\mathrm{Cr}$ content was determined by acid digestion (U.S. Environmental Protection Agency method 3010) and Inductive Coupled Plasma/ Optical Emission Spectrometry (ICP/OES) (USEPA method 6010B). The $\mathrm{Cr}(\mathrm{VI})$ content was determined by alkaline digestion (USEPA method 3060A) and colorimetric analysis (USEPA method 7196).

The samples were air-dried for $24 \mathrm{~h}$ and mechanically pulverized to fit into a U.S. standard \#400 sieve $(37 \mu \mathrm{m})$. Step-scanned X-ray powder diffraction (XRPD) data were collected by the Rigaku DXR 3000 computer-automated diffractometer using Bragg-Brentano geometry. The diffractometry was conducted at $40 \mathrm{kV}$ and $30 \mathrm{~mA}$ using a diffracted beam graphitemonochromator with a Cu radiation $(\lambda=1.54 \AA)$. The data were collected in the range of twotheta values between $5^{\circ}$ to $65^{\circ}$ with a step size of $0.05^{\circ}$ and a count time of 5 seconds per step. The qualitative analysis of the XRPD patterns was performed using the Jade software (version 7.0). In order to assess the quantitative distribution of the identified crystalline phases the Whole Pattern Fitting function of Jade was used. We used the PDF-2 set of the International Center for Diffraction Data database, and the Inorganic Crystal Structure Database as reference databases for powder diffraction and crystal structure respectively.

Air-dried samples were mounted on carbon coating and analyzed by Scanning Electron Microscopy and Energy Dispersive X-ray (SEM/EDX) using a LEO 982 Field emission scanning electron microscope with an Oxford energy dispersive $X$-ray analyzer

Micro X-ray fluorescence ( $\mu \mathrm{XRF}$ ) elemental mapping, micro X-ray diffraction ( $\mu \mathrm{XRD}$ ), and micro X-ray absorption near edge structure (XANES) spectroscopy measurements described here were performed on Beamline 10.3.2 of the Advanced Light Source, Lawrence Berkeley National Lab, CA, USA. The hard X-rays beam spot size was adjustable from $5 \times 5 \mu \mathrm{m}^{2}$ up to $16 \times 7 \mu \mathrm{m}^{2}$. Micro-XRF mapping shows chemical associations, e.g., between trace and major elements. We then selected some spots of interest on which to perform XRD; which tells us what the dominant minerals are in the probed volume. Micro-XANES yields information about the redox state of $\mathrm{Cr}$ as well as the relative abundance between the two states (trivalent and hexavalent). This beamline is described in detail in Manceau et al. (2002). Micro diffraction was performed with a Bruker SMART $6000 \mathrm{CCD}$. The incident beam energy was set to 17 $\mathrm{keV}$, which was high enough to perform XRD in transmission mode on the sample and provided access to reflections with d-spacings down to $1.24 \mathrm{~A}^{\circ}$. XRD Patterns were recorded for $10 \mathrm{~min}$ with a beam size of $16 \times 7 \mu \mathrm{m}^{2}$. Patterns were calibrated using alumina powder and XRD profiles were extracted using the Fit2d software. Peak indexing and subsequent processing were performed with the Jade software, as with the bulk XRD patterns. 


\section{RESULTS AND DISCUSSION}

The total $\mathrm{Cr}$ content of the soil was $21300 \mathrm{mg} \mathrm{kg}^{-1}$ and the $\mathrm{Cr}(\mathrm{VI})$ content was $4840 \mathrm{mg} \mathrm{kg}^{-1}$, or $23 \%$ of the total $\mathrm{Cr}$. This distribution is considered typical for grey black COPR samples from the SA7 site.

The mineralogy of the sample also represented the average mineralogy encountered in this type of material. Table 1 presents the quantitative mineralogy of the sample. Two CACs in different hydration states (12 and 14 water molecules) were detected in the sample, at $\sim 2 \%$ wt. each. This amount corresponds to $2950 \mathrm{mg} \mathrm{kg}^{-1}$ or $60 \%$ of the total $\mathrm{Cr}(\mathrm{VI})$ in the sample. Furthermore, hydrotalcites (sjoegrenite and quintinite) are also layered-minerals with a potential to host chromate in their interlayer. Katoite (member of the hydrogarnet group) was also detected and is a potential $\mathrm{Cr}(\mathrm{VI})$ host, as previously noted. Finally, ettringite is theoretically a host for $\mathrm{Cr}(\mathrm{VI})$, although experimental studies have shown that it is dominated by sulfate (Chrysochoou and Dermatas, 2006).

It should also be noted that $\mathrm{Cr}(\mathrm{VI})$ could be present in phases that are not detectable by XRD, either due to detection limit (estimated at $1 \mathrm{wt} \%$ for most COPR phases) or due to poor crystallinity. Sorption on iron surfaces is not a significant mechanism at pH 12.5 (Sposito, 1989).

Table1. Quantitative Bulk XRD results for the COPR sample

\begin{tabular}{ccc}
\hline & Chemical formula & \% wt. \\
\hline Brownmillerite & $\mathrm{Ca}_{2} \mathrm{FeAlO}{ }_{5}$ & 25.9 \\
Periclase & $\mathrm{MgO}$ & 2.2 \\
Brucite & $\mathrm{Mg}(\mathrm{OH})_{2}$ & 3.9 \\
Calcite & $\mathrm{CaCO}_{3}$ & 6.7 \\
Quartz & $\mathrm{SiO}_{2}$ & 2.8 \\
Katoite & $\mathrm{Ca}_{3} \mathrm{Al}_{2}(\mathrm{OH})_{12}$ & 13.3 \\
Quintinite & $\left.\mathrm{Al}_{2} \mathrm{Mg}_{4}(\mathrm{OH})_{12}(\mathrm{CO})_{3}\right)\left(\mathrm{H}_{2} \mathrm{O}\right)_{3}$ & 2.6 \\
Sjögrenite & $\left(\mathrm{Mg}_{6} \mathrm{Fe}_{2}(\mathrm{OH})_{16}\left(\mathrm{CO}_{3}\right)\left(\mathrm{H}_{2} \mathrm{O}\right)_{4}\right.$ & 3.6 \\
Afwillite & $\mathrm{Ca}_{3} \mathrm{Si}_{2} \mathrm{O}_{4}(\mathrm{OH})_{6}$ & 3.1 \\
Ettringite & $\mathrm{Ca}_{6} \mathrm{Al}_{2}(\mathrm{OH})_{12}\left(\mathrm{SO}_{4}\right)_{3} \cdot 26 \mathrm{H}_{2} \mathrm{O}$ & 1.3 \\
CAC* & $\mathrm{Ca}_{4} \mathrm{Al}_{2} \mathrm{O}_{6}\left(\mathrm{CrO}_{4}\right) \cdot 14 \mathrm{H}_{2} \mathrm{O}$ & 3.9 \\
Amorphous & & 31.0 \\
\hline
\end{tabular}

${ }^{*}$ CAC: Calcium Aluminum Chromium Oxide Hydrate

These preliminary results were then used as a basis to interpret the synchrotron based $\mu$ XAS and $\mu \mathrm{XRD}$ data. Figure 1a shows an optical image of the COPR thin section, as observed through a camera that enables navigation on the sample during the analysis. The white square shows the area, where $\mu \mathrm{XRF}$ mapping was performed.
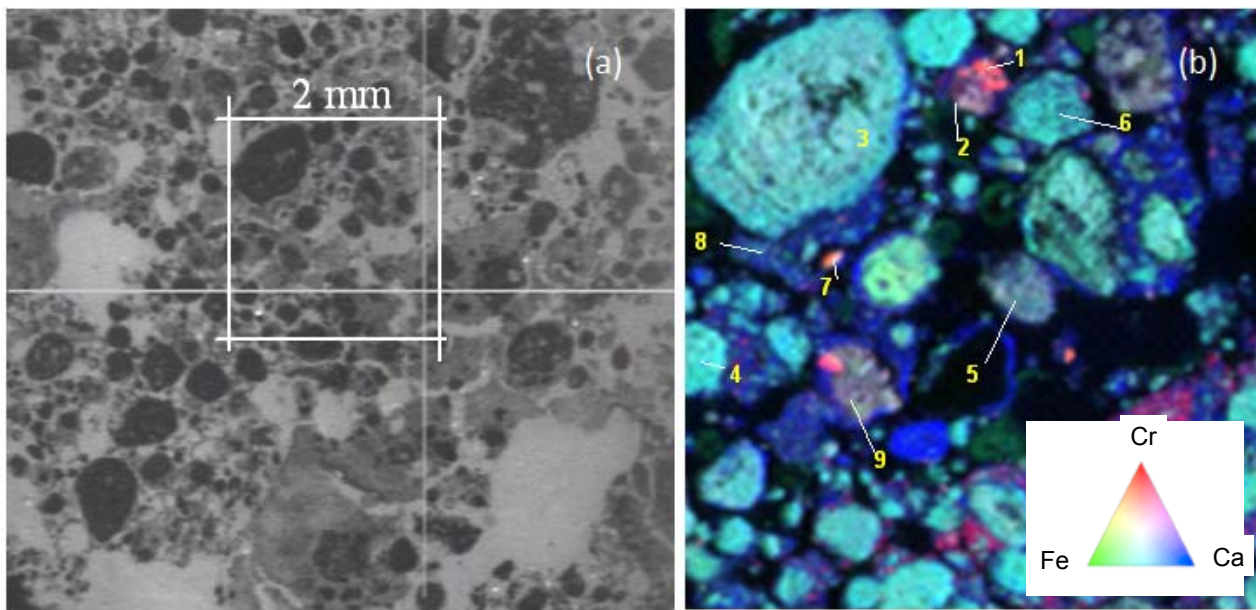

Figure 1. Optical image of COPR thin section (a) and XRF map of white square (Ca-blue, Fe-green, Cr-red) 
COPR is a very heterogeneous matrix. The dark areas (or nodules) are variable in size and shape, and are not compact, but contain different particles within, as shown in higher magnification. They are generally surrounded by a dark grey cementing matrix, which also exhibits significant heterogeneity. The light grey areas represent void space. The heterogeneity may indicate that investigating COPR thin sections in a statistically relevant manner is a challenging task. However, the analysis of various COPR thin sections indicates that the optical images have similar features, with the combination of nodules and cementing matrix. Still, the analysis of this area is presented as a sample of the approach adapted and not as all-encompassing dataset for the material properties,

Figure $1 \mathrm{~b}$ shows the tricolor XRF map of the square area. Along with $\mathrm{Cr}$, the $\mathrm{Ca}$ and $\mathrm{Fe}$ distributions are also displayed since they represent the major COPR metals (20.5 wt. $\%$ and $10.9 \mathrm{wt} \%$, respectively). Al and $\mathrm{Mg}$ are also important metals, but those elements are not accessible at beamline 10.3.2 due to limits on the available energy range ( $\mathrm{S}$ up to $\mathrm{Pb} \mathrm{L}_{3}$ ). As expected, the map shows that $\mathrm{Ca}$ is ubiquitous and associated with $\mathrm{Fe}$ in the interior of nodules. Fe seems to be present predominantly in the nodules, with very little to none in the cementing matrix. It is believed that this is because $\mathrm{Fe}$ is predominantly associated with brownmillerite, the COPR parent mineral, which is found in the nodules. When brownmillerite hydrates, iron precipitates as amorphous iron hydroxide and is not incorporated in the hydration products that make up the cementing matrix [6].

Bright $\mathrm{Cr}$ spots were observed on several regions, along with some diffuse $\mathrm{Cr}$-Ca rich areas (shown in purple on the map). It should be noted that the spot intensity may be misleading, because of the concentration of $\mathrm{Cr}$ in different minerals. For example, chromite $\left(\mathrm{FeCr}_{2} \mathrm{O}_{4}\right)$ contains $46 \mathrm{wt} . \% \mathrm{Cr}$, while the CACs only $8 \%$. Thus, chromite would appear as a bright red spot on the XRF map, while CACs or other $\mathrm{Cr}(\mathrm{VI})$ phases could be faint red or purple. Cr Kedge XANES was then performed on selected spots, marked as 1 through 9 in Figure 2.

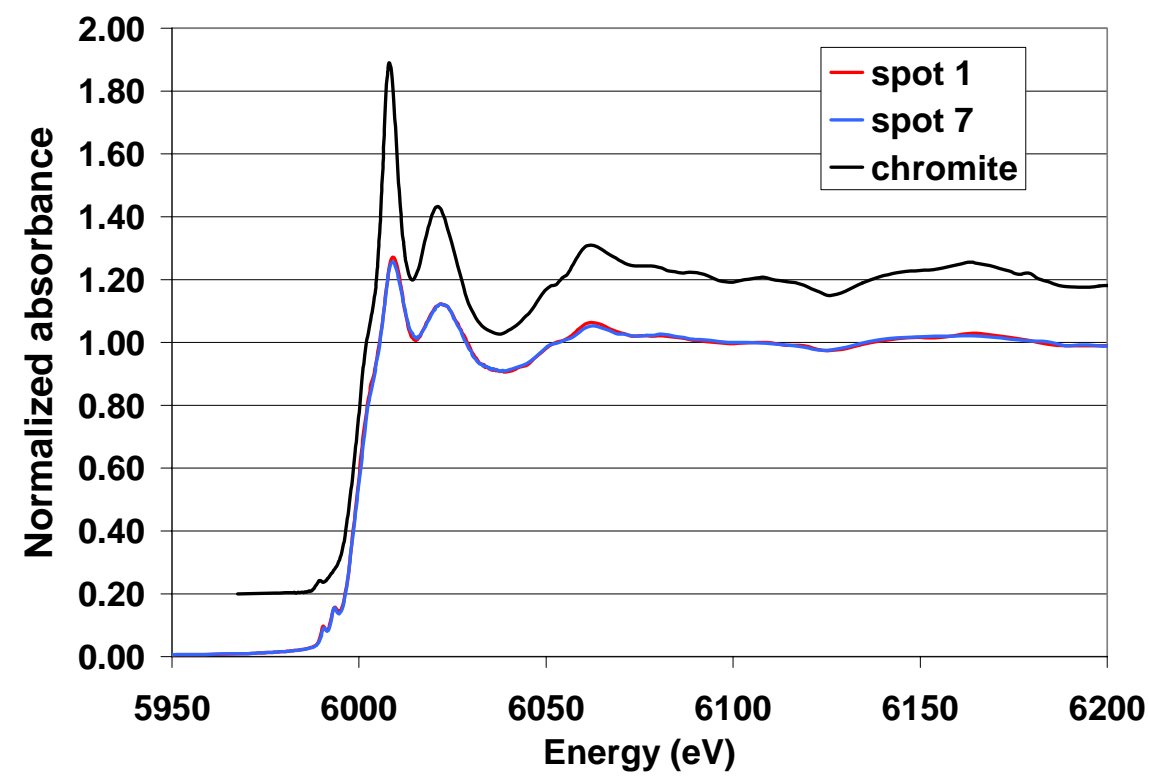

Figure 2. Normalized XAS spectra of spots 1 and 7 along with chromite $\left(\mathrm{FeCr}_{2} \mathrm{O}_{4}\right)$. The spectrum of chromite was shifted vertically for clarity

Figure 2 compares the XAS spectrum of the bright red spots 1 and 7 with the spectrum of pure chromite. Spots 1 and 7 yielded identical spectra, with good agreement with the pure chromite spectrum. A small $\mathrm{Cr}(\mathrm{VI})$ peak was observed at $5993 \mathrm{eV}$, which could be due to the presence of another phase in the $7 \times 16 \mu \mathrm{m}^{2}$ spot. Chromite was not identified in the bulk XRD pattern, because of the small residual amount $(\sim 1-2 \%)$ left in COPR, but it was observed in other COPR XRD patterns and in SEM (Chrysochoou, 2006). Small differences between the XANES spectra of spots 1 and 7 and to pure chromite can be attributed to the fact that chromite in COPR is not a pure phase but contains $\mathrm{Mg}, \mathrm{Al}$ and trace $\mathrm{Ti}$. Thus, the conclusion that bright red spots are probably associated with $\operatorname{Cr}(\mathrm{III})$ minerals and specifically chromite, was confirmed by this observation. 




Figure 3. XAS spectra of the remaining spots compared to pure $\mathrm{K}_{2} \mathrm{CrO}_{4}$

Figure 3 shows the XAS spectra of the six remaining spots. A narrower energy region was chosen compared to figure 3 to facilitate the comparison between the seven spectra. All six spots exhibited the characteristic pre-edge feature at $5993 \mathrm{eV}$ that signals the presence of $\mathrm{Cr}(\mathrm{VI})$. The post-edge spectrum of the spots was very different from that of potassium chromate, suggesting a different electronic configuration of the chromate anion in the structures that bind it. The post-edge spectra of the spots were, however, very similar, with the exception of spot 4 that exhibited a minor difference at $6010 \mathrm{eV}$. This finding suggests that $\mathrm{Cr}(\mathrm{VI})$ was bound in phases with similar structure in the analyzed spots. The peak height was variable, ranging from 20 to $50 \%$ the peak height of $\mathrm{K}_{2} \mathrm{CrO}_{4}$, which indicates that the amount of bound chromate varied, even though the electronic configuration was similar.

The XRD analyses of spots 4 through 9 showed that multiple minerals were present in most of the patterns, indicating that the spot size was too large to isolate individual $\mathrm{Cr}(\mathrm{VI})$-bearing phases. Furthermore, a large background due to scattering of the substrate, the glass and the air rendered the positive identification of phases difficult. However, some preliminary conclusions were drawn from the analysis of the patterns. Figure 5 and 6 shows the patterns of spot 9 as characteristic examples.

CACs were not identified in any of the XRD patterns, even though they account for $60 \%$ of the total $\mathrm{Cr}(\mathrm{VI})$, according to bulk XRD. This confirms the previous observation, that a statistically significant analysis via microstructural methods requires the analysis of extensive areas and/or multiple samples. However, this was suitable for the purposes of the analyses because the objective was to identify other $\mathrm{Cr}(\mathrm{VI})$-bearing phases, not the known CACs. No peaks were identifiable in spot 4 , which had a slightly different XAS pattern than other phases. Thus, the phase was either amorphous to X-rays, or could not be identified due to the high background. Spot 5 contained brownmillerite, katoite and sjoegrenite. Both latter phases are potential $\mathrm{Cr}(\mathrm{VI})$ hosts, as previously noted. Spot 6 had a high $\mathrm{Cr}(\mathrm{VI})$ peak in the XANES spectrum and a pronounced katoite peak, along with some brownmillerite. This finding confirms the hypothesis that hydrogarnet acts as a $\mathrm{Cr}(\mathrm{VI})$ host in COPR. Spot 8, which had the highest $\mathrm{Cr}(\mathrm{VI})$ intensity in the XANES spectrum contained sjoegrenite and a peak at dspacing $2.56 \AA$, which could not be identified. Spots 6 and 8 had almost identical XAS spectra, but different phase assemblages in XRD. This is a surprising finding that requires further investigation. Finally, spot 9 contained a pronounced peak of chromatite $\left(\mathrm{CaCrO}_{4}\right)$, along with some traces of other COPR phases (see figure 5). Chromatite is a mineral of relatively high solubility compared to other cement phases and is not predicted as a stable phase by geochemical modeling (Chrysochoou and Dermatas, 2005). It was also not identified in any of the bulk XRD patterns at SA7 (Chrysochoou, 2006), most probably because it was below the XRD detection limit. 


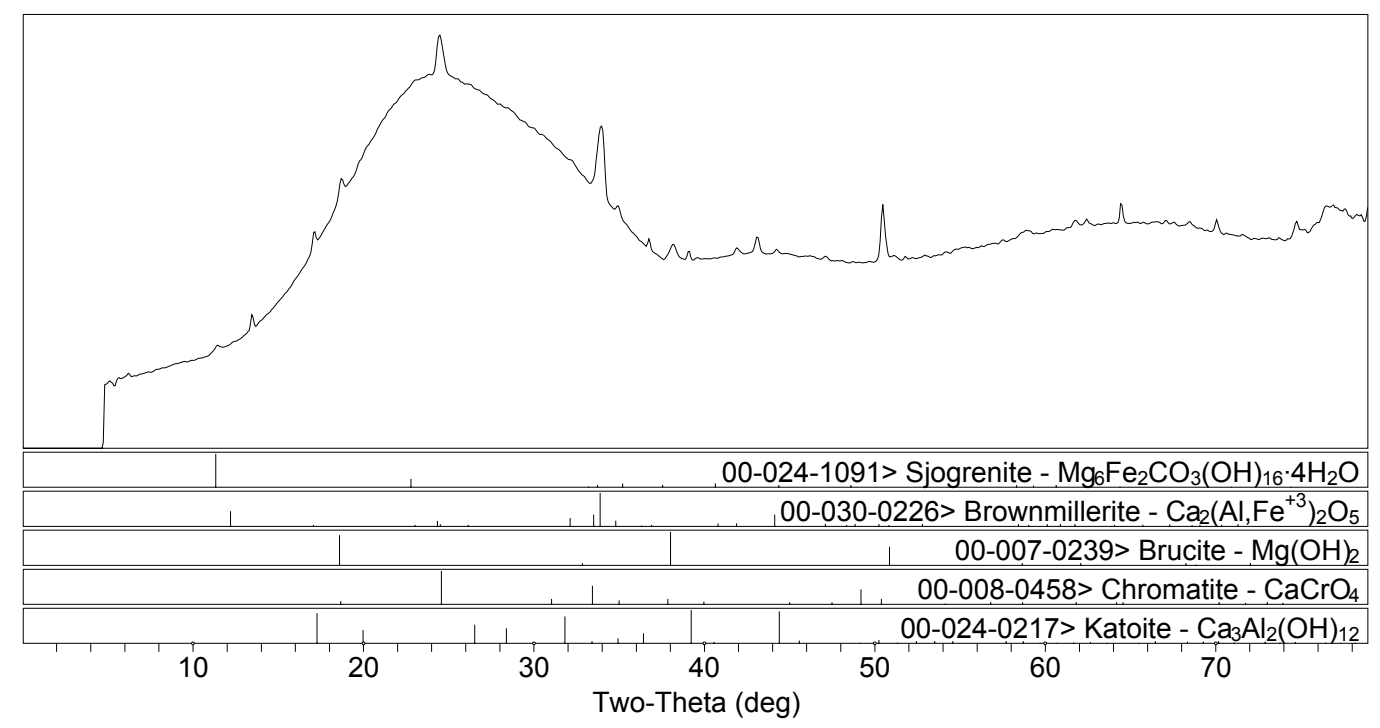

Figure 4. XRD pattern collected on spot 9

\section{CONCLUSIONS}

The speciation of $\mathrm{Cr}(\mathrm{VI})$ in Cromite Ore Processing Residue was investigated by means of bulk XRD, and a combination of micro-XRF, - XAS and -XRD. Bulk XRD yielded one group of phases that contained explicitly $\mathrm{Cr}(\mathrm{VI})$ in their structure, Calcium Aluminum Chromium Oxide Hydrates. Accounting for $60 \%$ of the total $\mathrm{Cr}(\mathrm{VI})$. Micro-XRF has shown the presence of several $\mathrm{Cr}$ hot spots, as well as weaker, more diffuse signals associated with $\mathrm{Ca}$. $\mathrm{Cr} \mathrm{K}$ edge XANES analysis on the hotspots showed that they were associated with the presence of residual chromite, containing little or no $\mathrm{Cr}(\mathrm{VI})$. The latter was observed in the more diffuse spots, and the spectra of several of the spots were similar, indicating similar electronic configurations around the chromate anion. The XRD results on the same spots yielded different phases, including katoite (hydrogarnet), hydrotalcite and chromatite.

Overall, the combination of these analysis enabled the positive identification of $\mathrm{Cr}(\mathrm{VI})$-bearing phases that were only speculated sinks thus far, as well as the identification of phases below the bulk XRD detection limit. More work is required in larger areas and more samples to obtain better statistics. The beamline enables the acquisition of $\mathrm{Cr}(\mathrm{VI})$ maps over entire sample areas, significantly improving the understanding of $\mathrm{Cr}(\mathrm{VI})$ presence within the matrix and providing a better platform to conduct micro-XANES and micro-XRD analyses. This type of information cannot be obtained by any other experimental method and constitutes valuable information for $\mathrm{Cr}(\mathrm{VI})$ release and treatment.

\section{ACKNOWLEDGMENTS}

The operations of the Advanced Light Source at LBNL are supported by the Director, Office of Science, Office of Basic Energy Sciences, US Department of Energy under contract number DEAC02-05CH11231.

\section{REFERENCES}

Allied Signal (1982), 'Process Descriptions Baltimore Plants'

Chrysochoou M., (2006), Investigation of environmental and geotechnical implications associated with deposition of Chromite Ore Processing Residue (COPR). Ph.D. dissertation, Stevens Institute of Technology, Hoboken, NJ, U.S.A.

Chrysochoou M. and Dermatas D., (2005), Comparison of geochemical modeling in Chromite Ore Processing Residue using MINTEQ and EQ3/6 software, Proceedings 9th Conference on Environmental Science and Technology, Rhodos, Greece.

Chrysochoou M. and Dermatas D., (2006), Evaluation of Ettringite and Hydrocalumite Formation for Heavy Metal Immobilization: Literature Review and Experimental Study, Journal of Hazardous Materials, 136(1), 20-33. 
Chrysochoou M. and Dermatas D., (2007), Application of the Rietveld method to assess $\mathrm{Cr}(\mathrm{VI})$ speciation in Chromite Ore Processing Residue, Journal of Hazardous Materials, 141(2), 370377.

Dermatas D., Bonaparte R., Chrysochoou M. and Moon D.H., (2006a), Chromite Ore Processing Residue: Hazardous Contaminated Soil or Solid Waste?, Journal of ASTM International, 3(7), (doi: 10.1520/JAl13313).

Dermatas D., Chrysochoou M., Moon D.H., Grubb D.G, Wazne M. and Christodoulatos C., (2006b), Ettringite-Induced Heave in Chromite Ore Processing Residue (COPR) upon Ferrous Sulfate Treatment, Environmental Science and Technology, 40(18), 5786-5792.

Hillier S., Lumsdon D.G., Brydson R., Paterson E., (2007), Hydrogarnet: a host phase for $\mathrm{Cr}(\mathrm{VI})$ in Chromite Ore Processing Residue (COPR) and other high pH wastes, Environmental Science and Technology, 41, 1921-1927.

Lioy P.J., Freeman N.C.G., Wainman T., Stern A.H., Boesch R., Howell T. and Shupack S.I., (1992), Microenvironmental analysis of residential exposure to chromium-laden wastes in and around New Jersey homes, Risk Analysis, 12, 287-299.

Manceau A., Marcus M.A. and Tamura N., (2002a), Quantitative speciation of heavy metals in soils and sediments by synchrotron X-ray techniques. In Applications of Synchrotron Radiation in Low-Temperature Geochemistry and Environmental Science, 49, 341-428.

Sposito G., (1989),. The chemistry of soils, Oxford University Press, New York. 